\title{
Pusat Terapi Oksigen dengan Penerapan Konsep Green Building di Pulau Gili Iyang Madura
}

\author{
Vivi Aida, Amin Sumadyo, Ummul Mustaqimah \\ Program Studi Arsitektur \\ Fakultas Teknik \\ Universitas Sebelas Maret, Surakarta \\ Email: vivieaidaiii@gmail.com
}

\begin{abstract}
Gili Iyang Island has high oxygen level potential which is more than $20 \%$ with lower pollution percentage compared to other regions in Indonesia. The result of oxygen in Gilli Iyang Island was done by LAPAN in 2006 and BBTKL-PP in 2013. It reached 20,9\% up to 21,5\%. The oxygen level affects Gili Iyang Island becoming tourist destination to take oxygen therapy. However, the activity isn't supported by adequate facilities, so that an oxygen therapy center is necessary to meet those needs. The design proposal rises a problem is designing a healthy oxygen therapy facility that hold the local natural circumstance. Environmental issues in Gili Iyang Island which is still pure and healthy responded by Green Building concept application in Oxygen Therapy Center. The Oxygen Therapy Center focusing on the application of green building concept to respond the environmental issue of Gili Iyang Island. The Green Building concept based on six criterias in accordance with the Greenship: Green Building Council Indonesia (GBCI): appropriate land use, energy efficiency and conservation, water conservation, resource and material cycle, health and comfort in space, and environmental management building. The concept is trying to afford a healthy and nature-synergy building design so than it can support oxygen therapy process and energy-saving building. The main design concepts are site cultivation, mass system, shape and appearance of the building, material selection, exterior of the building, also building utilities.
\end{abstract}

Keywords: Gili Iyang Island, Oxygen Therapy, Green Building Concept, Greenship: Green Building Council Indonesia (GBCI)

\section{PENDAHULUAN}

Pulau Gili Iyang merupakan sebuah pulau kecil yang mulai dikenal masyarakat luas. Pulau ini terletak di dekat Pulau Madura tepatnya di Kabupaten Sumenep. Pulau Gili Iyang mulai dikenal masyarakat karena memiliki potensi wisata alam dan potensi kadar oksigen yang tinggi (di atas ambang normal 20\%) dibandingkan dengan wilayah lain di Indonesia. Berdasarkan penelitian terakhir yang dilakukan Balai Besar Teknis Kesehatan Lingkungan dan Pengadilan Penyakit (BBTKLPP), kondisi oksigen $\left(\mathrm{O}_{2}\right)$ mencapai 20,9 hingga $21,5 \%$ atau berada di atas ambang normal $20 \%$. Kondisi kadar karbondioksida (CO2) di pulau ini berkisar antara 302-313 ppm, berada di bawah ambang batas normal yang diperbolehkan di udara sebesar 387 ppm (BBTKL-PP Surabaya, 2013). Kondisi udara yang bersih dengan kadar oksigen yang tinggi dan potensi wisata alam menyebabkan Pemerntah Kabupaten Sumenep berencana menjadikan Pulau Gili Iyang sebagai ikon wisata kesehatan alam.

Potensi kadar oksigen yang tinggi memberikan daya tarik tersendiri bagi wisatawan. Berdasarkan data jumlah pengunjung Pulau Gili Iyang, wisatawan meningkat dari tahun ke tahun hingga pada tahun 2015 mencapai angka 7.933 orang (Dinas Kebudayaan, Pariwisata, Pemuda, dan Olahraga Kabupaten Sumenep, 2016). Tujuan wisatawan mengunjungi pulau ini adalah menikmati kadar oksigen secara alami atau melakukan terapi oksigen. Terapi oksigen adalah memasukkan oksigen tambahan dari luar ke paru dengan menggunakan metode tertentu seperti hiperbarik, relaksasi, dan olahraga (Standar Pelayanan ICU, 2008). Kegiatan terapi oksigen yang dilakukan wisatawan tidak didukung dengan sarana dan prasarana yang memadahi sehingga diperlukan sebuah fasilitas terapi oksigen guna mewadahi kegiatan tersebut (surabayapost.co.id, 2013). 
Pengembangan wilayah Pulau Gili Iyang dengan membuat sebuah bangunan baru maka tidak dapat dipungkiri bahwa daur hidup gedung akan mempengaruhi keadaan alam setempat. Perencanaan pusat terapi oksigen akan meminimalkan konsumsi energi serta dampak negatif dari daur ulang bangunan. Penerapan konsep Green Building merupakan langkah tepat untuk menjaga keseimbangan antara lingkungan binaan dan lingkungan setempat.

Penerapan Konsep Green Building didasarkan pada enam kriteria yang dijabarkan oleh Greenship: Green Building Council Indonesia (GBCI) yaitu tepat guna lahan, efisiensi dan konservasi energi, konservasi air, sumber dan siklus material, kesehatan dan kenyamanan dalam ruang, serta manajemen lingkungan bangunan. Konsep Green Buildingberupaya untuk menghadirkan sebuah desain bangunan yang sehat dan bersinergi dengan alam Pulau Gili Iyang sehingga mampu mendukung proses terapi oksigen pada pengguna Pusat Terapi Oksigen, serta menghadirkan bangunan yang dapat menghemat konsumsi energi.

\section{METODE}

Perencanaan pusat terapi oksigen menggunakan metode penerapan konsep Green Building. Konsep Green Building yang diterapkan didasarkan pada Greenship: Green Building Council Indonesia (GBCI) 2013 yang menerapkan enam standar dimana suatu gedung dapat dikatakan sebagai gedung hijau dan gedung yang ramah lingkungan. Enam standar kriteria menurut GBCI adalah tepat guna lahan, efisiensi dan konservasi energi, konservasi air, sumber dan siklus material, kesehatan dan kenyamanan dalam ruang, serta manajemen lingkungan bangunan. Enam standar kriteria dari Greenship ini menjadi dasar analisis untuk mendapatkan analisis ruang, tapak, bentuk dan tampilan, pemilihan material, struktur, serta utilitas.

Penerapan konsep Green Building pada desain berfokus pada enam standar kriteria dari Greenship yaitu:

1. Tepat guna lahan diterapkan pada pengolahan tapak dengan memperhatikan lansekap, fasilitas pengguna sepeda, dan keseimbangan dengan alam setempat.
2. Efisiensi dan konservasi energi diterapkan pada pemanfaatan pencahayaan dan penghawaan alami melalui desain pasif pada bangunan.

3. Konservasi air diterapkan pada penghematan air dengan mendaur ulang limbah dan penggunaan sumber air alternatif.

4. Sumber dan siklus material diterapkan pada pemilihan material yang ramah lingkungan, memiliki nilai albedo rendah, serta mudah didapatkan di Pulau Gili Iyang.

5. Kesehatan dan kenyamanan dalam ruang diterapkan pada sistem pencahayaan dan penghawaan alami, serta kenyamanan visual pengguna gedung.

6. Manajemen lingkungan bangunan diterapkan pada pengelolaan limbah gedung dan pengolahan ekologi sekitar bangunan.

\section{ANALISIS}

Berikut analisis perencanaan Pusat Terapi Oksigen di Pulau Gili Iyang:

\subsection{Analisis Ruang}

\subsubsection{Tujuan}

Kebutuhan ruang pada Pusat Terapi Oksigen di Pulau Gili Iyang.

\subsubsection{Dasar Pertimbangan}

1. Studi preseden

2. Kriteria kelompok kegiatan dan pola kegiatan di dalamnya

\subsubsection{Hasil}

1. Kegiatan penerimaan

2. Kegiatan terapi oksigen hiperbarik.

3. Kegiatan relaksasi.

4. Kegiatan olahraga.

5. Kegiatan penunjang.

6. Kegiatan pengelola pusat.

7. Kegiatan servis.

\subsection{Analisis Tapak 3.2.1 Tujuan}

Tapak yang ideal dan sesuai dengan kebutuhan operasional gedung dan standar Green Building.

\subsubsection{Dasar Pertimbangan}

1. Terletak di luar kawasan wisata Gua Air Pulau Gili Iyang.

2. Terintegrasi dengan pelabuhan dan jalan lingkar utama. 
3. Ketersediaan lahan kosong, mudah dalam pembebasan, dan bukan merupakan area greenfield.

\subsubsection{Hasil}

Tapak terpilih Pusat Terapi Oksigen berada pada sisi selatan Desa Bancamara berbatasan langsung dengan Pantai Propet (lihat Gambar 1.). Luas tapak terpilih adalah $32.100 \mathrm{~m}^{2}$. Eksisting tapak berbatasan dengan jalan lokal $3 \mathrm{~m}$ (utara), jalan lingkar utama $4 \mathrm{~m}$ (timur), Pantai Propet (selatan), dan jalan lokal $3 \mathrm{~m}$ (barat). Peraturan bangunan pada tapak didasarkan pada kriteria penyediaan sarana dan prasarana pemukiman Pulau Gili Iyang yang diterbitkan oleh Pusat Penelitian dan Pengembangan Pemukiman Kementrian Umum dan Perumahan Rakyat (PUPR) dengan ketentuan:

KDB maksimal 40\%, KLB maksimal 80\%, ketinggian bangunan maksimum 2 lantai, GSB muka minimum 3,75 m, GDB samping kanan, kiri, dan belakang minimal 2-4 $\mathrm{m}$.

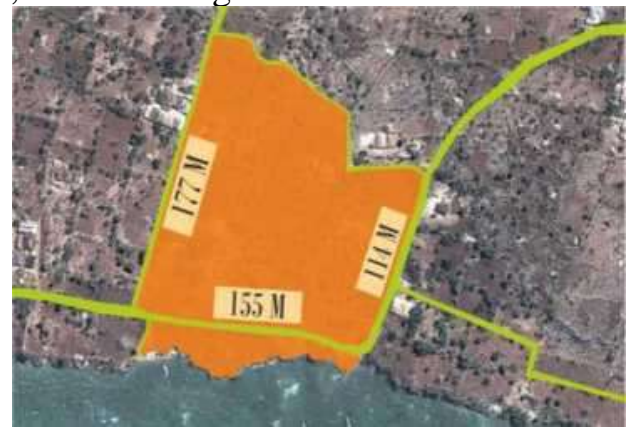

Gambar 1. Tapak terpilih pada Perencanaan Pusat Terapi Oksigen terletak pada lahan yang memiliki orientasi kea rah view alam Pantai Propet.

\subsection{Analisis Pencapaian}

\subsubsection{Tujuan}

Akses utama menuju lokasi perancangan atau main entrance (ME) dan side entrance (SE).

\subsubsection{Dasar Pertimbangan}

1. Kemudahan pencapaian dari jalan utama.

2. Menyesuaikan arus lalu lintas jalan lingkar utama.

3. Kemudahan akses yang ditempuh dari jalan dan berkaitan langsung dengan tapak bagi seluruh pengguna.

\subsubsection{Hasil}

Berikut merupakan konsep pencapaian pada pusat terapi oksigen:
1. ME terletak pada sisi timur tapak diperuntukkan untuk pejalan kaki, sepeda, dan becak (lihat Gambar 2.).

2. SE terletak pada sisi timur tapak. SE dan ME mempunyai jalur yang sama pada tapak.

3. Akses loading dock terletak pada arah timur menuju arah selatan pada tapak.

4. Akses pengguna menuju Pantai Propet terletak pada sisi selatan tapak diperuntukkan untuk pejalan kaki.

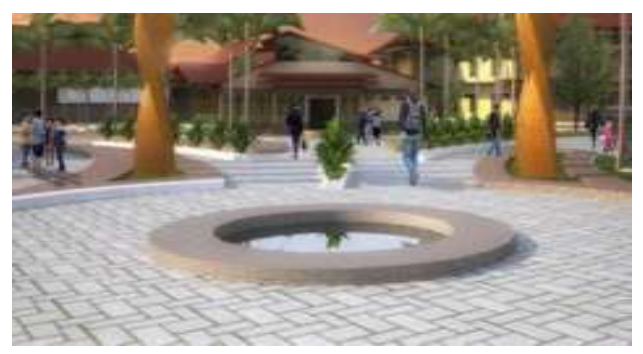

Gambar 2. Main Entrance pada timur tapak

\subsection{Analisis Pemintakatan}

\subsubsection{Tujuan}

Pemintakan ruang berdasarkan pencapaian kebutuhan dan hierarki ruang yang tepat pada tapak.

\subsubsection{Dasar Pertimbangan}

1. Pencapaian ke dalam tapak.

2. Kebutuhan dan hirarki ruang yang berhubungan dengan fungsi masingmasing kelompok.

3. Kelompok kegiatan pada masing-masing kelompok ruang.

\subsubsection{Hasil}

Berikut merupakan konsep pemintakatan pada pusat terapi oksigen (lihat Gambar 3.):

1. Zona cottage food court dan coffee shop berada pada sisi selatan tapak.

2. Zona fasilitas terapi oksigen hiperbarik dan relaksasi berada pada sisi selatan tapak.

3. Zona servis dan pengelola berada pada sisi barat tapak.

4. Zona pusat informasi berada pada sisi timur tapak dekat dengan main entrance. 


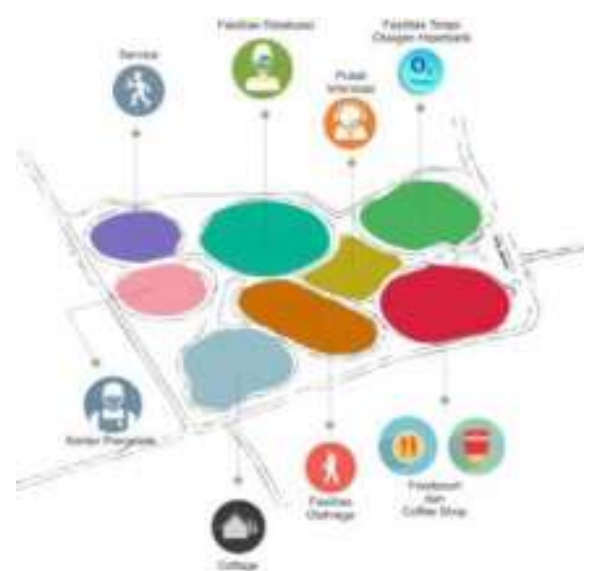

Gambar 3. Pemintakatan pada Pusat Terapi Oksigen

\subsection{Analisis Tata Massa Bangunan 3.5.1 Tujuan}

Bentuk dan tatanan massa yang sesuai dengan tapak dan mempertimbangkan pemintakatan dan orientasi keseluruhan tapak.

\subsubsection{Dasar Pertimbangan}

1. Tata letak pemintakatan masing-masing kelompok kegiatan.

2. Orientasi tata massa bangunan pada tapak.

3. Massa bangunan memiliki fungsi yang berdekatan dan memiliki kesamaan visual agar tercipta satu kesatuan/ unity.

\subsubsection{Hasil}

Massa bangunan pada Pusat Terapi Oksigen merupakan massa majemuk yang memiliki Sembilan massa bangunan. Sembilan massa bangunan ini memiliki fungsi yang berbedabeda pada masing-masing bangunannya sehingga dibedakan menurut kelompok kegiatan. Perbedaan pada masing-masing bangunan memiliki keterkaitan dengan fungsi utama yaitu terapi oksigen sehingga penataan massa pada kompleks bangunan menggunakan komposisi cluster (lihat Gambar 4.).

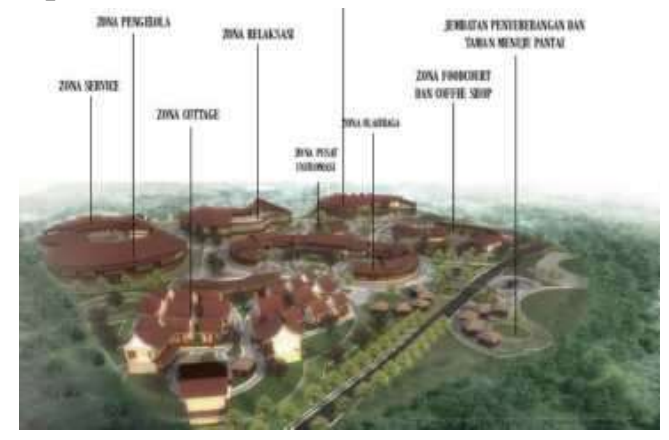

Gambar 4. Tata Massa pada Kawasan Pusat Terapi Oksigen

\subsection{Analisis Klimatologi Matahari 3.6.1 Tujuan}

Volume bangunan dan fasad bangunan yang berhubungan dengan kenyamanan termal bangunan.

\subsubsection{Dasar Pertimbangan}

1. Arah edar matahari pada tapak.

2. Faktor-faktor kenyamanan termal pada sebuah ruangan/bangunan.

\subsubsection{Hasil}

1. Volume pada masing-masing bangunan dipecah menjadi beberapa massa kembali guna merespon siklus sinar matahari dalam tapak. Pemecahan massa berfungsi untuk mengurangi beban panas pada bangunan (lihat Gambar 5.)

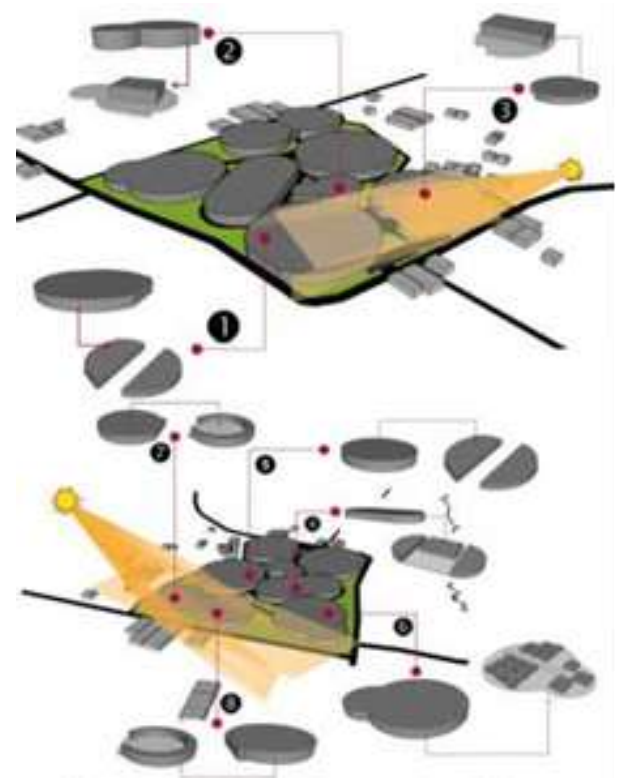

Gambar 5. Hasil Pemecahan Massa Bangunan

2. Barrier bangunan berupa secondary skin, overhang (lihat Gambar 6.). Sementara bukaan berupa desain fasad dengan partisi yang terbuka dan pemanfaatan daylight dengan penggunaan skyling dan lubang pada atap bangunan (lihat Gambar 7.). 


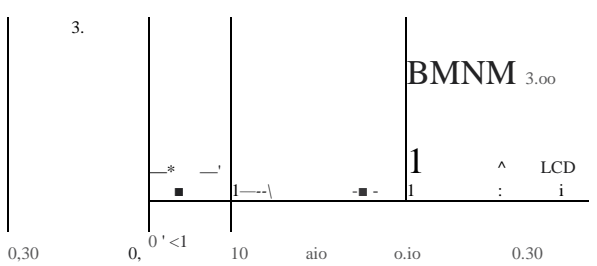

Gambar 6. Wall Garden sebagai barrier

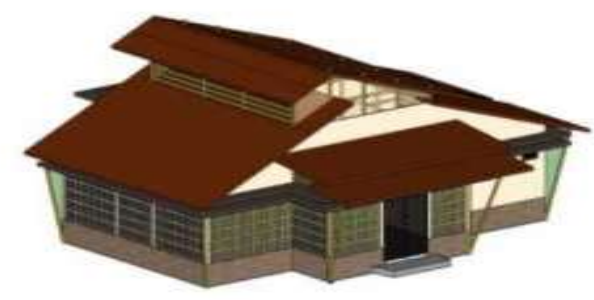

Gambar 7. Sky light dan lubang pada atap

\subsection{Analisis View}

\subsubsection{Tujuan}

Respon desain terkait dengan koneksi ruang terhadap ruang luar.

\subsubsection{Dasar Pertimbangan}

1. Akses menuju tapak.

2. Arah pandang dari luar ke dalam tapak ataupun sebaliknya untuk mendapatkan area ekspos ternaik.

3. View potensial di luar tapak.

\subsubsection{Hasil}

Tinggi bangunan pada massa bangunan yang dekat dengan view potensial memiliki tinggi 4 $\mathrm{m} / 1$ lantai, lebih pendek dibandingkan dengan massa bangunan yang terletak pada bagian dalam tapak yang memiliki tinggi $8 \mathrm{~m} / 2$ lantai. Perencanaan view buatan pada masingmasing zona dengan taman, open space dan gazebo yang berfungsi sebagai tempat bersantai pengunjung sambil menghirup udara dengan kadar oksigen tinggi (lihat Gambar 8.). View buatan berfungsi untuk memberikan koneksi lingkungan luar dan dalam ruang serta memberikan kenyamanan visual pada pengguna bangunan (lihat Gambar 9.).

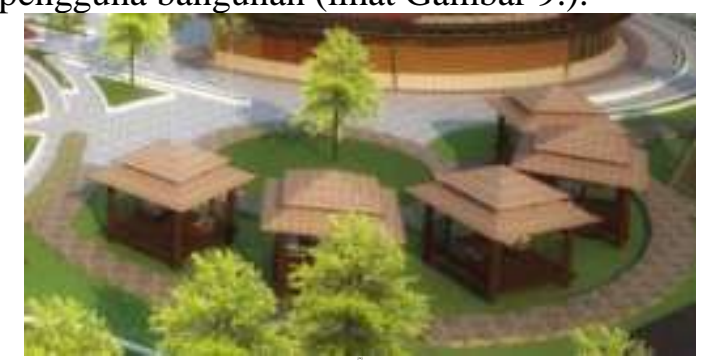

Gambar 8. View buatan pada kawasan

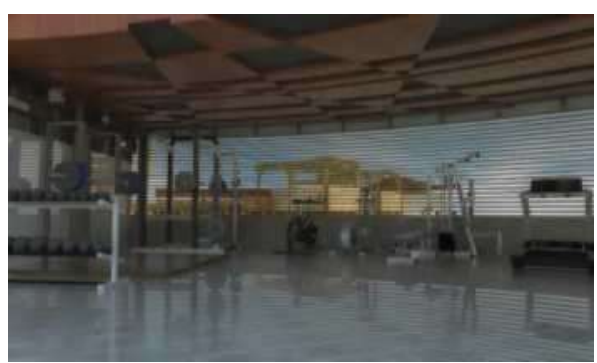

Gambar 9. View ke luar bangunan

\subsection{Analisis Bentuk Bangunan \\ 3.8.1 Tujuan}

Bentuk dan gubahan massa yang mampu mewadahi kegiatan di dalamnya yang sesuai dengan konsep Green Building.

\subsubsection{Dasar Pertimbangan}

1. Sesuai dengan tata massa cluster pada tata massa kawasan pusat terapi oksigen.

2. Sesuai dengan respon bangunan terkait respon klimatologi matahari.

3. Sesuai dengan fungsi bangunan yang menyuguhkan fasilitas terapi.

\subsubsection{Hasil}

Bentuk bangunan yang dipilih adalah bentuk lengkung yang cenderung pada bentuk-bentuk lingkaran. Karakter bentuk lingkaran menurut fungsi adalah sebagai karakter yang tidak kau, mempunyai nilai estetika yang lebih utama untuk memberikan kesan informal. Bentuk lengkung sesuai dengan jenis sirkulasi yang diterapkan pada sirkulasi kawasan yaitu sirkulasi organik (lihat Gambar 10.).

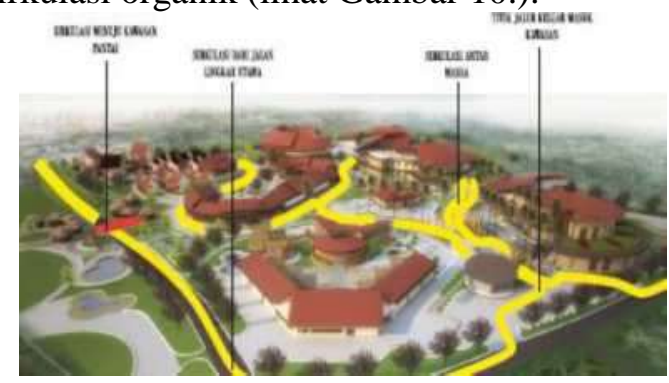

Gambar 10. Sirkulasi Organik pada Kawasan

Pemilihan bentuk lengkung dapat mengarahkan angina sehingga angina akan mengikuti bentuk bangunan. Bentuk yang dipilih merupakan bentuk-bentuk ramping sehingga beban panas yang diterima oleh bangunan dapat dikurangi. Bentuk ramping diwujudkan dengan cara memecah massa masif, pengurangan bentuk dasar bangunan agar bentuk menjadi ramping dan beban panas 
dapat dikurangi, serta cahaya matahari dapat masuk menjangkau seluruh bagian bangunan. Berikut merupakan pemilihan bentuk dan gubahan massa pada Pusat Terapi Oksigen (lihat Gambar 11. dan Gambar 12.).

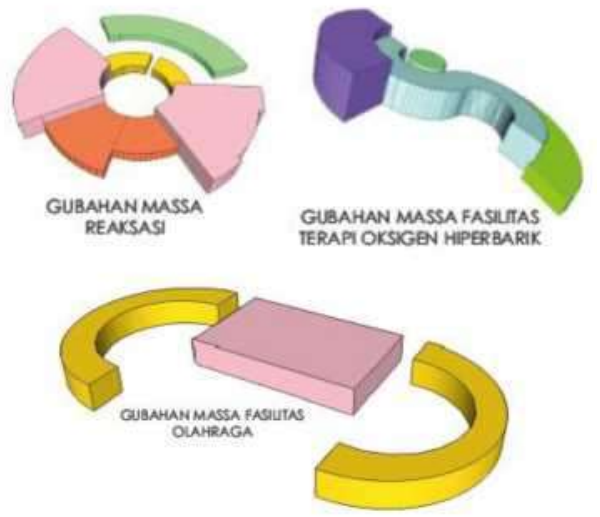

Gambar 11. Gubahan Massa pada Bangunan

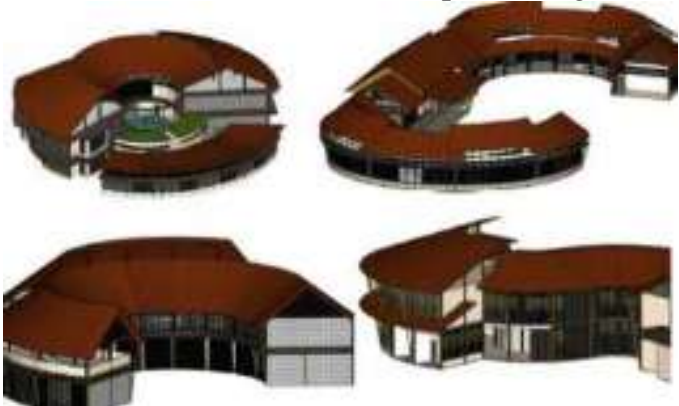

Gambar 12. Penerapan Bentuk Lengkung pada Massa Bangunan

\subsection{Analisis Tampilan Bangunan 3.9.1 Tujuan}

Tampilan bangunan yang mempertimbangkan aspek Green Building pada perancangan Pusat Terapi Oksigen.

\subsubsection{Dasar Pertimbangan}

1. Kesesuaian karakter bangunan dengan karakter budaya setempat terkait arsitektur tradisional.

2. Kesesuaian dengan karakteristik konsep Green Building kaitannya dengan sun shading, pemilihan jenis atap, dan pemilihan warna material bangunan.

\subsubsection{Hasil}

Pemilihan bentuk atap yang mempunyai derajat kemiringan dan pengolahan bentuk atap dengan adanya naik turun atap untuk memasukkan cahaya dan udara dari luar bangunan (lihat Gambar 13.). Penggunaan overhang sepanjang lantai 1 dan lantai 2 untuk memberikan perlindungan terhadap radiasi matahari agar tidak langsung mengenai dinding bangunan sehingga radiasi panas dapat tereduksi. Penggunaan fasad terbuka dengan menggunakan partisi dan dinding berlubang pada bangunan (lihat Gambar 14.).

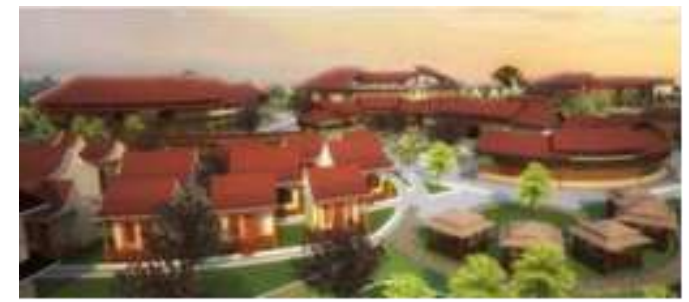

Gambar 13. Pemilihan Atap pada Bangunan Pusat Terapi Oksigen

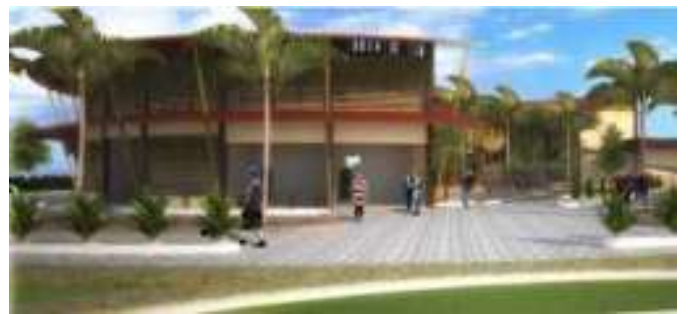

Gambar 14. Fasad Bangunan

\subsection{Analisis Pemilihan Material 3.10.1 Tujuan}

Memilih material lokal yang ramah lingkungan dan sesuai dengan konsep Green Building terkait material bangunan sebagai elemen dari desain pasif bangunan.

\subsubsection{Dasar Pertimbangan}

1. Material lokal yang tersedia di Pulau Gili Iyang.

2. Material yang ramah lingkungan.

3. Material alam yang mempunyai nilai albedo rendah.

\subsubsection{Hasil}

Material yang diterapkan pada Pusat Terapi Oksigen adalah material yang ramah lingkungan dan merupakan material-material alam. Material alam yang digunakan adalah material kayu yang merupakan kayu lokal berasal dari Pulau Gili Iyang. Kayu digunakan sebagai fasad bangunan untuk partisi, selain itu terdapat penggunaan batu alam, lantai kayu, serta penggunaan atap bitumen yang merupakan atap hasil daur ulang dan ramah lingkungan. 


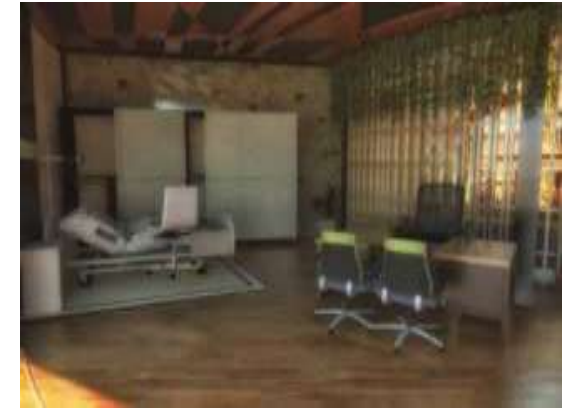

Gambar 15. Pemilihan Material pada Pusat Terapi Oksigen

\subsection{Analisis Lansekap}

\subsubsection{Tujuan}

Lansekap berdasarkan kriteria konsep green building.

\subsubsection{Dasar Pertimbangan}

1. Vegetasi eksisting pada tapak.

2. Pemilihan vegetasi untuk konsep softscape dan pemilihan material untuk konsep hardscape.

3. Pengolahan tapak yang sesuai dengan konsep Green Building.

\subsubsection{Hasil}

Penataan lansekap pada lahan Pusat Terapi Oksigen didasarkan pada ketentuan greenship dan kriteria yang ada di Pulau Gili Iyang yaitu sebanyak 50\% dari lahan yang terbangunkan dengan rincian luas lahan adalah $32.100 \mathrm{~m}^{2}$, dengan luas lantai dasar sebesar $13.734 \mathrm{~m}^{2}$. Penataan lansekap pada Pusat Terapi Oksigen dibagi menjadi 2 bagian yaitu softscape dan hardscape. Penataan softscape adalah berupa pemilihan vegetasi lokal yaitu menggunakan pohon kelapa dan palem pantai sehingga vegetasi lokal tidak dihilangkan sama sekali. Pengolahan tapak memperhatikan pengguna sepeda dengan pemilihan hardscape berupa grassblock yang bisa berfungsi sebagai biopori. Fasilitas untuk pengguna sepeda adalah adanya sirkulasi khusus yang tidak licin dan parker sepeda pada masing-masing zona (lihat Gambar 16.).

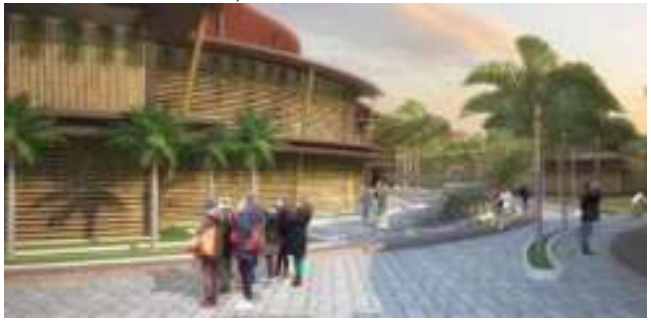

Gambar 16. Fasilitas bagi pengguna sepeda

\subsection{Analisis Konservasi Air 3.12.1 Tujuan}

Reduksi penggunaan konsumsi air pada operasional dan pengguna gedung.

\subsubsection{Dasar Pertimbangan}

1. Sumber air pada tapak Pusat Terapi Oksigen.

2. Jenis air dan pengolahan air tersebut.

3. Pengolahan limbah dan air hujan.

\subsubsection{Hasil}

Sumber air, pengolahan air, dan penampungan air hujan merupakan satu kesatuan yang akan digunakan dalam operasional masing-masing gedung pada kawasan Pusat Terapi Oksigen. Pengolahan sumber air pada kawasan Pusat Terapi Oksigen adalah sebagai berikut:

1. Air sumur pada kawasan Pusat Terapi Oksigen merupakan air payau, sumber air ini digunakan untk kebutuhan sehari-hari pengguna gedung dan memenuhi kebutuhan air pengguna. Pengolahan air payau menggunakan proses reserve osmosis yang dikelompokkan menjadi tiga macam yaitu pengolahan secara destilasi, penukaran ion, dan filtrasi (lihat Gambar 17.).

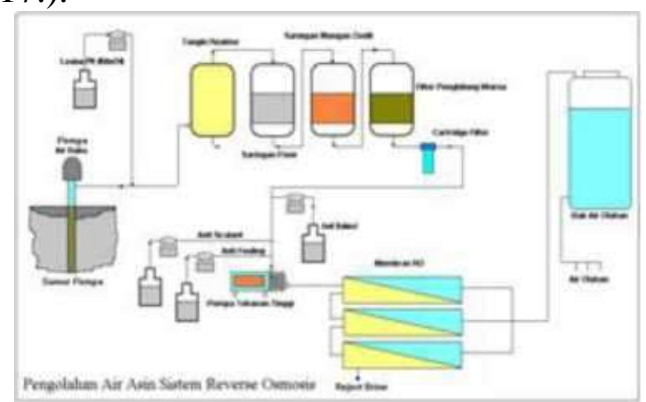

Gambar 17. Pengolahan air payau

2. Sistem Pemanfaatan Air Hujan (SPAH) terdiri atas system Penampungan Air Hujan (PAH) dan sistem Pengolahan Air Hujan. PAH dilengkapi dengan talang air, saringan pasir, bak penampung, dan Sumur Resapan. Air hujan dimanfaatkan untuk flushing dan penyiraman tanaman. Pengolahan air grey water dilakukan melalui IPAL dengan sistem biofilter anaerob-aerob yang dilengkapi dengan bak ekualisasi. Grey water dimanfaatkan unruk flushing dan penyiraman tanaman. 


\section{KESIMPULAN}

Pusat Terapi Oksigen sebagai fasilitas terapi oksigen mewadahi kegiatan terapi oksigen dengan metode hiperbarik, relaksasi, olahraga. Kompleks pusat terapi oksigen ditunjang dengan fasilitas lain yaitu food court, coffee shop, dan cottage. Isu lingkungan Pulau Gili Iyang yang masih alami dan fungsi bangunan sebagai terapi oksigen maka penerapan yang dipilih adalah konsep Green Building. Penerapan konsep Green Building pada bangunan diharapkan dapat memberikan sebuah desain bangunan sehat dan dampak negatif bangunan dapat direduksi.

Penerapan konsep Green Building didasarkan pada enam standar kriteria yang ditetapkan oleh Greenship: Green Building Council Indonesia antara lain: tepat guna lahan, efisiensi dan konservasi energi, konservasi air, sumber dan siklus material, kesehatan dan kenyamanan dalam ruang, serta manajemen lingkungan bangunan.

Penerapan enam kriteria konsep Green Building ini diharapkan bangunan Pusat Terapi Oksigen memiliki desain yang hemat konsumsi oksigen sehingga dampak negatif terhadap bangunan dapat diminimalisasi. Oleh karena itu, Pusat Terapi Oksigen akan didesain dengan menerapkan konsep Green Building. Hal yang akan dilakukan antara lain:

1. Mendesain area lansekap bangunan dengan memperhatikan keseimbangan lingkungan binaan dan lingkungan setempat. Pengolahan sirkulasi, pemilihan material, dan fasilitas untuk kendaraan tidak bermotor.

2. Desain bentuk dan fasad bangunan yang merupakan elemen desain pasif untuk menghemat konsumsi energi dengan memperhatikan pencahayaan dan penghawaan alami (lihat Gambar 18.).

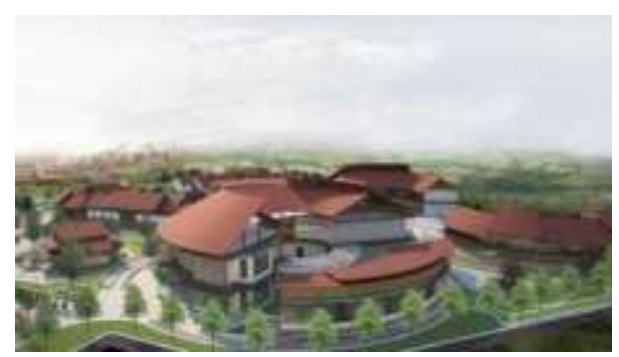

Gambar 18. Desain bentuk dan fasad bangunan
3. Menghemat penggunaan air pada daur hidup bangunan dengan cara merencanakan sumber alternatif air, pengolahan limbah grey water, dan menggunakan air hujan sebagai sumber air alternatif.

4. Pemilihan material lokal dan ramah linkgungan pada bangunan.

5. Mendesain bangunan agar ruang dalam dapat terkoneksi dengan ruang luar sehingga pengguna dapat memiliki kenyamanan visual (lihat Gambar 19.).

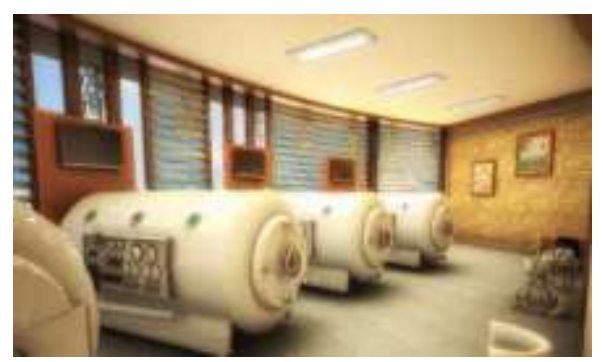

Gambar 19. Kenyamanan Visual dalam Ruang

6. Mengolah limbah bangunan agar dampak negatif bangunan terhadap lingkungan setempat tereduksi.

\section{REFERENSI}

Badan Perencanaan Pembangunan Daerah Kabupaten Sumenep, Penerbangan dan Antariksa Nasional. 2006. Penelitian Kondisi Lingkungan Pulau Gili Iyang sebagai Potensi Kawasan Wisata Kesehatan. Bandung: LAPAN.

Balai Besar Teknik Kesehatan Lingkungan dan Pengendalian Penyakit (BBTL-PP) Surabaya. 2013. Laporan Kajian Kualitas Lingkungan dan Faktor Resiko Kesehatan di Kawasan Wisata Gili Iyang Kabupaten Sumenep Tanggal 1-3 Mei 2013. Surabaya: BBTKL-PP.

Dinas Kebudayaan, Pariwisata, Pemuda, dan Olahraga Kabupaten Sumenep. 2015. Laporan Jumlah Wisatawan Kabupaten Sumenep dan Pulau Gili Iyang Periode 2010 - 2015. Sumenep: Pemerintah Kabupaten Sumenep.

Direktorat Keperawatan dan Keteknisan Medik Direktorat Jenderal Pelayanan Medik. 2008. Standar Pelayanan 
Keperawatan di ICU. Jakarta : Departemen Kesehatan.

Nasir, Ratna Y. 2013. Panduan Teknis: Perangkat Penilaian Bangunan Hijau untuk Bangunan Baru Versi 1.2,. Jakarta: World Green Building Council Indonesia.

Surabaya Post. 2015. Wisata Kesehatan yang Terabaikan.

http://www.surabayapost.co.id/baca/2008/ 06/15/wisata-kesehatan-yang-terabaikan.

Diakses pada 25 Agustus 2015, 16:01 